\title{
Relationships between Potential Risk of Hazardous Material Releases and Socio-Economic Demographic Characteristics Using Geospatial Analysis
}

\author{
Seong Nam Hwang, Venu Srivastav Kannegalla \\ Environmental Science Program, Department of Biology, Southeast Missouri State University, Cape Girardeau, USA \\ Email: shwang@semo.edu,vkannegalla1s@semo.edu
}

How to cite this paper: Hwang, S. N., \& Kannegalla, V. S. (2021). Relationships between Potential Risk of Hazardous Material Releases and Socio-Economic Demographic Characteristics Using Geospatial Analysis. Journal of Geoscience and Environment Protection, 9, 62-85.

https://doi.org/10.4236/gep.2021.97005

Received: June 12, 2021

Accepted: July 18, 2021

Published: July 21, 2021

Copyright $\odot 2021$ by author(s) and Scientific Research Publishing Inc. This work is licensed under the Creative Commons Attribution International License (CC BY 4.0).

http://creativecommons.org/licenses/by/4.0/

\begin{abstract}
The problem investigated in this research is about the potential risk of technological hazards, which poses a perilous threat to humankind and the environment. Rapid urbanization has been increasing the population density in an area, elevating the risk of exposure to technological disasters. Therefore, it is necessary to detect the areas with higher chemical risk to spread awareness about the potential risk zones and reduce actual damage and casualties resulting from the hazardous substance events. The basic design of the study utilizes geospatial analysis to map the TRI (Toxics Release Inventory) facilities in the communities of Texas to establish a relationship between potential hazardous material release zones and the human population at risk. The study identified the vulnerable counties as well as investigated how those risk areas are related to race/ethnicity, income and education. The research would contribute to the policymakers acting on the hazard situation and keep them better prepared for chemical hazards. In addition, it would help the residents and emergency managers to better understand the circumstance to mitigate the consequences as well as increase their awareness to be ready for the uncertainties in the hotspots involved in high risk of the hazards.
\end{abstract}

\section{Keywords}

Environmental Hazard, Risk, GIS, Disaster, Hazard Mitigation, Emergency Management, Toxics Release Inventory (TRI) Facilities and Socioeconomic Demographic Characteristics 


\section{Introduction}

Technological hazards can be defined as a threat to the natural and manmade environment, including human beings and their properties, which results from various human actions such as producing, shipping, storing, and utilizing toxic chemical materials. Those human-made hazards can have a negative influence on almost all communities, requiring their collective action to prepare and respond to a technological disaster and mitigate the negative impacts of such environmental threats. Therefore, stakeholders, particularly local governments, should identify which geographic areas are at risk and what segments of their population are vulnerable to the hazard before enforcing any collective actions to protect lives and properties from it. To this end, this research is designed to investigate how the scientifically estimated risk of hazardous material releases is associated with community at the levels of census tracts and counties in the state of Texas. One of the main goals of this research is to analyze hazardous material-related risk and how it is associated with social, economic, and demographic factors such as race, ethnicity, educational attainment and poverty. In addition, this study aims to identify specific locations in the state with the highest level of concentration of the TRI (Toxics Release Inventory) facilities dealing with toxic chemicals that can claim human injuries and deaths. TRI is a database that contains information about "toxic chemical releases and pollution prevention activities" conducted by businesses and governments (EPA, 2021).

A hazardous material has any one or more characteristic properties (e.g., ignitability, corrosivity, reactivity, toxicity), leading to harmful effects on human beings, property, and the environment. Such hazards include toxic waste, air/water pollution, fires and explosions, radioactive accidents, and hazardous material spills or releases (Kates \& Kasperson, 1983; Flores et al., 2021). Technological advancements and the development of the human lifestyle have also had the other side. Along with increasing benefits, we should be prepared for the risk of generating an equal amount of hazardous material. There has been an upsurge in the use and production of industrial chemicals with rapid evolution resulting from having increased the industrial revolution. Such a phenomenon has been evidenced in each of the countries of the world regardless of their developmental or economic status where its industrialization has resulted in increased exposure to hazardous chemicals (Xu et al., 2020; Ak et al., 2020; Poku-Boansi et al., 2018; Thakur et al., 2018; Andersen et al., 2017). It is apparent that human exposure to harmful substances, in turn, increases health-related problems. These risks of exposure to various toxic chemicals vary according to the spatial distance, socioeconomic factors, and environmental levels (Lowry et al., 1995). In general, technological disasters result from the use of improper equipment and equipment failure and failure to follow safety procedures. However, a chemical accident may often be related to a natural disaster. For example, at the time of natural disasters such as earthquakes, hurricanes, and tornadoes, power outages very often occur. It could be due to strong wind or storm surges which can result in damaging 
electrical equipment in an industrial facility holding unstable, reactive chemical compounds maintained at a lower temperature, eventually causing leakage of hazardous chemicals into the environment (Santella et al., 2010, Flores et al., 2021). Much literature has addressed these problems at different geographic levels, making it hard for policymakers to follow and understand the current state of knowledge. The empirical research conducted by $\mathrm{Li}$ and his colleagues attempted to identify a geospatial pattern in which the exposure to industrial toxic chemicals can be consistently controlled (Li et al., 2016). However, the amplified abundance of hazardous materials has increased risk to human health, property, or the environment. Previous studies show effects and causes of increased mortality and morbidity of fatal diseases and ailments in the population (Gong et al., 2018; Palmer et al., 2006). The Bhopal disaster that occurred in December 1984 at the Union Carbide India Limited is one of the worst chemical disasters in history, which took more than 2,000 lives in few days (Sriramachari, 2004).

There is empirical evidence that such chemical disasters disproportionately have influenced minorities or arisen from racial and ethnic minority groups such as African Americans and Hispanics. For instance, a study performed in the metropolitan area of Atlanta, Georgia, United States showed a scenario of the area in which low socioeconomic status populations and minorities are more likely to be exposed to potentially harmful chemicals (Johnson et al., 2016). The authors also claimed that lower socioeconomic status and non-White communities were disproportionately exposed to hazardous substances.

The accidental release of toxic substances during transportation, process, treatment, and discharge to the environment tends to increase the exposure to toxic material (Quddus et al., 2018). The risk of exposure to hazardous materials can be estimated with the amount of those produced in the manufacturing process. A few facts about the amount of toxic release in Texas compared to the US are presented in Table 1. The TRI program administered by the Environmental Protection Agency asks private and federal facilities dealing with hazardous substances to report their hazardous chemicals that may lead to "cancer or other chronic human health effects, or adverse environmental effects." It is notable that Texas accounts for about 8.4 percent of the total number of TRI facilities in the United States while it generates around 3.9 billion pounds of toxic waste, about $13 \%$ of the total production-related waste managed in the U.S. (EPA, 2019). The unwanted exposure needs to be analyzed and requires modeling at adequate levels of geographic resolution, which could reveal exposure inequalities by income and race (Dolinoy \& Miranda, 2004).

As described earlier, continuous exposure to toxic materials may intensify the immediate and long-term impacts on public health. Variables regarded as a measuring factor to decide the human exposure scenario may include socioeconomic status, ethnicity, and literacy rate. Some research has been done to investigate relationships between technological hazards and socio-demographic factors (Sohrabi et al., 2020; Malecha et al., 2020; Batisse et al., 2017; Johnston et al., 2016; 
Table 1. TRI quick facts.

\begin{tabular}{lll}
\hline & Texas & United States \\
\hline No. of TRI Facilities: & 1782 & 21,458 \\
Total Production-Related Waste Managed: & 3.9 billion lbs. & 30.6 billion lbs. \\
Total On-site and Off-site Disposal or Other Releases: & 188.6 million lbs. & 3.4 billion lbs. \\
Total On-site: & 158.7 million lbs. & 2.9 billion lbs. \\
- Air: & 50.6 million lbs. & 600.2 million lbs. \\
• Water: & 17.2 million lbs. & 201.2 million lbs. \\
• Land: & 90.9 million lbs. & 2.1 billion lbs. \\
Total Off-Site: & 29.8 million lbs. & 456.5 million lbs. \\
\hline
\end{tabular}

Source: EPA (2019).

Maantay, 2007; Thomas et al., 2002; Chakraborty, 2020; Sheppard et al., 1999). However, little research has utilized GIS (Geographic Information System) to investigate how technological hazards correlate with socio-demographic characteristics even though GIS-based environmental risk assessment has been extensively used since the 1990s. As a matter of fact, GIS enables researchers to represent a complex geographical distribution of geospatial data. It is proved to be one of the best ways of representing various geographical issues that are georeferenced for natural hazards such as earthquakes, landslides, floods, and technological hazards such as hazardous material releases (Senouci et al., 2021). Additionally, various geoprocessing tools in ArcGIS can be used to analyze complex data sets that contain attributes about diverse populations and geographic locations at risk of those hazards (Zhao \& Liu, 2017).

For this research, GIS was used to georeference the individual TRI facility locations in Texas to identify the possible scenarios estimated and listed in risk of exposure. To be more specific, various GIS tools such as Proximity, Extract, Overlay, Data management, and Spatial Analyst, helped analyze relationships between the potential exposure risk of hazardous material from the TRI and the socioeconomic demographic characteristics across Texas. Representation of the TRI facility and community data through GIS is expected to provide a picture of the current situation about how the technological hazard is associated with the socioeconomic demographic variables. It will help policymakers and the mitigation personnel to conclude how to mitigate the hazard and protect their citizens against the risk (Dolinoy \& Miranda, 2004). These research findings are meaningful, considering that they help local governments better prepare to protect their communities against human-made hazards such as biological or chemical threats.

\section{Data and Methods}

The study area of this research includes all the counties in Texas which the second-largest populated state in the US. It has been reported to experience $23.25 \%$ 
of the total events recorded in the category called Hazardous Substances Emergency Events Surveillance (Wattigney et al., 2009). It is noticeable that much of the state has been plagued with a wide range of perilous technological hazards and chemical accidents). The incidents involved fixed facility events, estimated to be $25.3 \%$ of all fixed facility events and $18 \%$ of events during transportation. Hundreds of petrochemical manufacturing and distribution facilities are situated along the Gulf of Mexico and significant metropolitan areas (Dallas-Fort WorthArlington and San Antonio New Braunfels). These locations lead to a significant risk of hazardous material releases in their operation or transportation, threatening public health and safety and disrupting the natural and manmade environment. It becomes essential to track these events to understand the cause, dimensions, and aftereffects. The State of Texas consists of 322 counties and 23 metropolitan areas, including the Dallas-Fort Worth-Arlington including Dallas County, the Houston-The Woodlands-Sugar Land including Harris County, and the Austin-Round Rock-San Marcos (or Greater Austin), including Travis County. It is noticeable that the TRI facilities dealing with toxic chemicals are concentrated in these three metropolitan areas.

The main objective of the research is to utilize geospatial technology to enumerate communities and the human population most vulnerable to technological hazards. These hazards are related to TRI facilities dealing with toxic chemicals that can claim human injuries and deaths. To examine how the geographical pattern of the chemical risk is associated with the different populations such as white, black, Asian, and Hispanic people at the county and census tract level in Texas. In addition, this research will capture how the risk is related to social and economic factors such as educational attainment and poverty. Its primary goal is to contribute to a research community by providing knowledge about how human-induced hazards can influence different populations' segments.

Two major types of datasets were collected to conduct the research. One is the geospatial data showing each location of the industrial and federal facilities required to report to Environmental Protection Agency information about hazardous chemical releases through its TRI program every year. The EPA's program was designed to better manage over 690 hazardous materials from over 20,000 US industrial facilities that may threaten public health and the environment when released into the air, water, and soil. There were 1817 TRI facilities in Texas as of 2015. The other is the dataset about socio-demographic characteristics such as race, ethnicity, level of education, and income collected through the Bureau of Census. The dataset also includes census tract and county boundaries, containing information about socio-demographic characteristics (e.g., race, ethnicity, educational attainment, and income level) as attributes in each data table. The attributes come from the 2014-2018 ACS (American Community Survey) 5 -Year estimates.

These data imported into ArcMap for geospatial analysis and projected into the USA Contiguous Albers Equal Area coordinate system helped analyze the effects of the potential health risk of toxic chemical releases on the communities 
in Texas through GIS-based spatial analysis. Various analytical methods that will be employed include geoprocessing operations (such as Buffer, Clip, Intersection, and Dissolve, and Point Density analysis). The results of this geospatial analysis created maps that represent information on the geographic locations of the facilities dealing with hazardous materials and human populations and socioeconomic and demographic factors that can be influenced by the potential risk of hazardous substances escaping into the environment.

\section{Results}

Each of the Figures 1(a)-(d) provides a choropleth map layer showing the percentage of the white, black, Hispanic, and Asian population by county in Texas, respectively. Each of which is overlaid with a dot density layer showing the number of TRI facilities (used as a proxy to the risk of hazardous material releases) to represent relationships between race/ethnicity and the risk. These maps give a quick overview of where both a specific population group and the hot spots of the TRI facilities are concentrated. In general, Figure 1(a) and Figure 1(d) show that the higher the representation of the black or Asian people residing in the higher chemical risk zones, while Figure 1(b) and Figure 1(c), the higher percentage of the white or Hispanic population, living in the lower-risk zones. The settlement of population sets in low and high-risk zones suggests that the white and Hispanic people tend to reside in a county with a lower risk level of toxic materials. In contrast, the black and Asian people, comparatively, have a higher risk level. Figure 1(e) and Figure 1(f) represent an association between the number of TRI facilities closer to one county centroid than the other and the white or black population percentage, respectively.

It should be noted that those counties with no red triangle symbol have no single TRI facility that is closest to each county. Overall, this map clearly shows that the white population has a propensity to live in a county far away from TRI facilities. At the same time, the black population is near TRI facilities. On the other hand, Figure 1(g) and Figure 2(h) capture a relationship between a distance from a facility point to a county boundary closest to the point and the white and black population percentage, respectively. A TRI facility point that falls inside a county was regarded as being closest to the county, receiving zero meters. This map suggests that the black population tends to reside in areas disproportionately vulnerable to technological hazards.

As a more in-depth geospatial analysis, each of the race/ethnicity categories (i.e., Low, Medium, and High) was given values of one, two, three, respectively, to represent a race-specific population concentration index. Map layers representing racial/ethnic were dissolved into three classes (or indices) based on the Quantile Method, where features (i.e., 254 counties) were aggregated in equal numbers, (i.e., 85 counties each in each index) and plotted on each map as shown in Figures 2(a)-(d). The index of 0 indicates the lowest concentration of a race/ethnicity while the index of 3 , the highest concertation of the same race/ethnicity. 


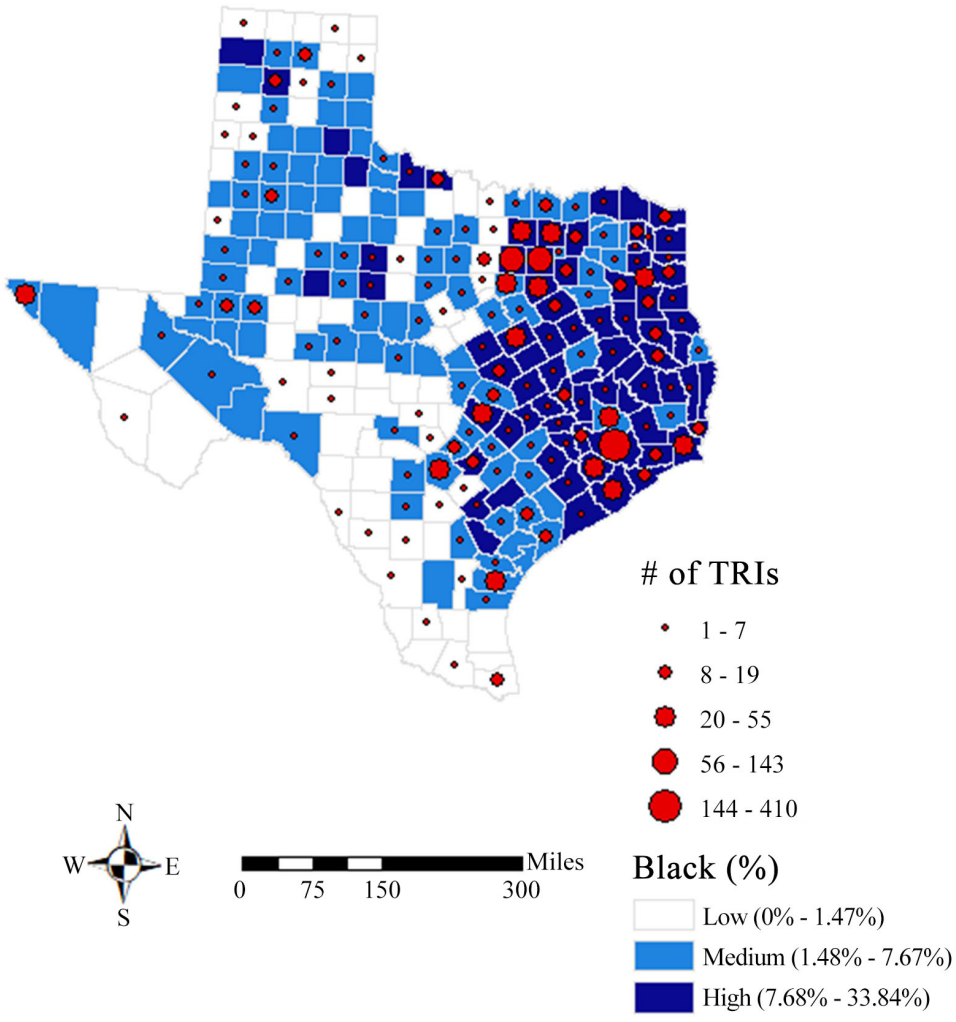

(a)

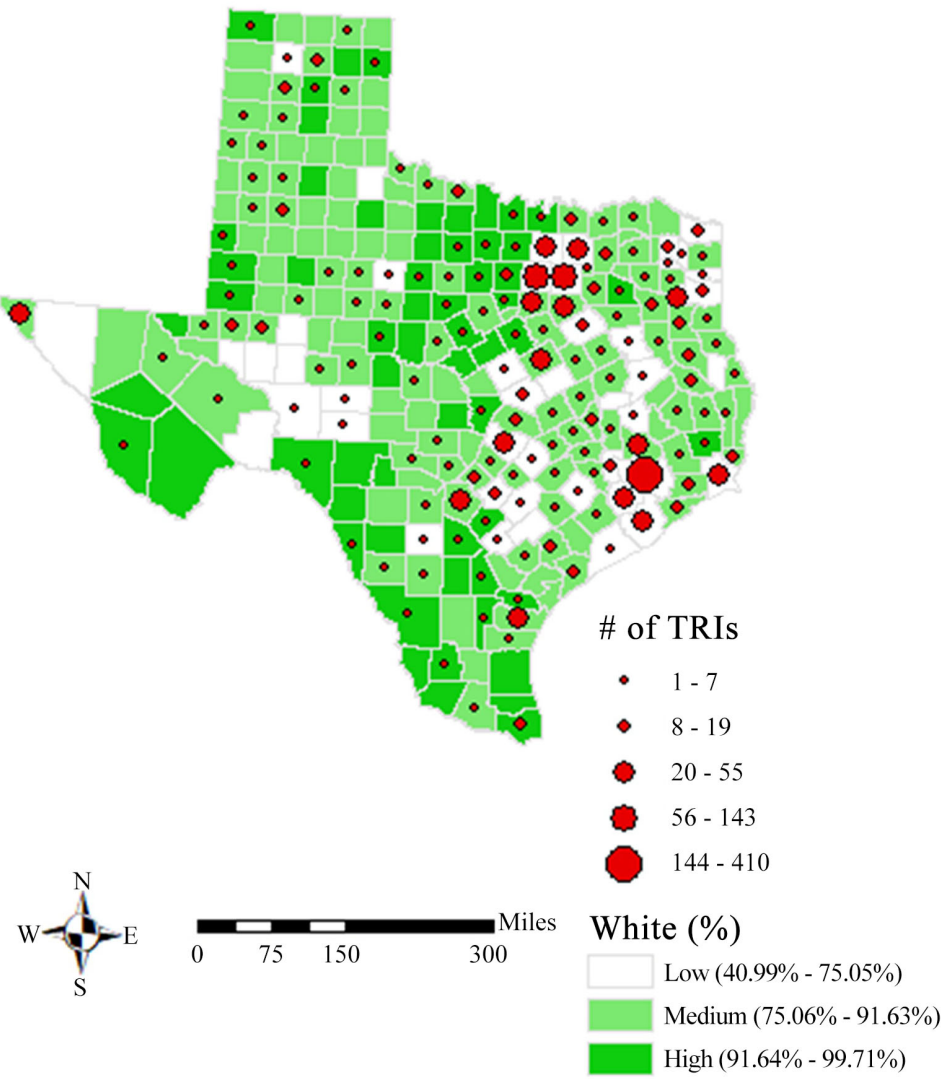

(b) 


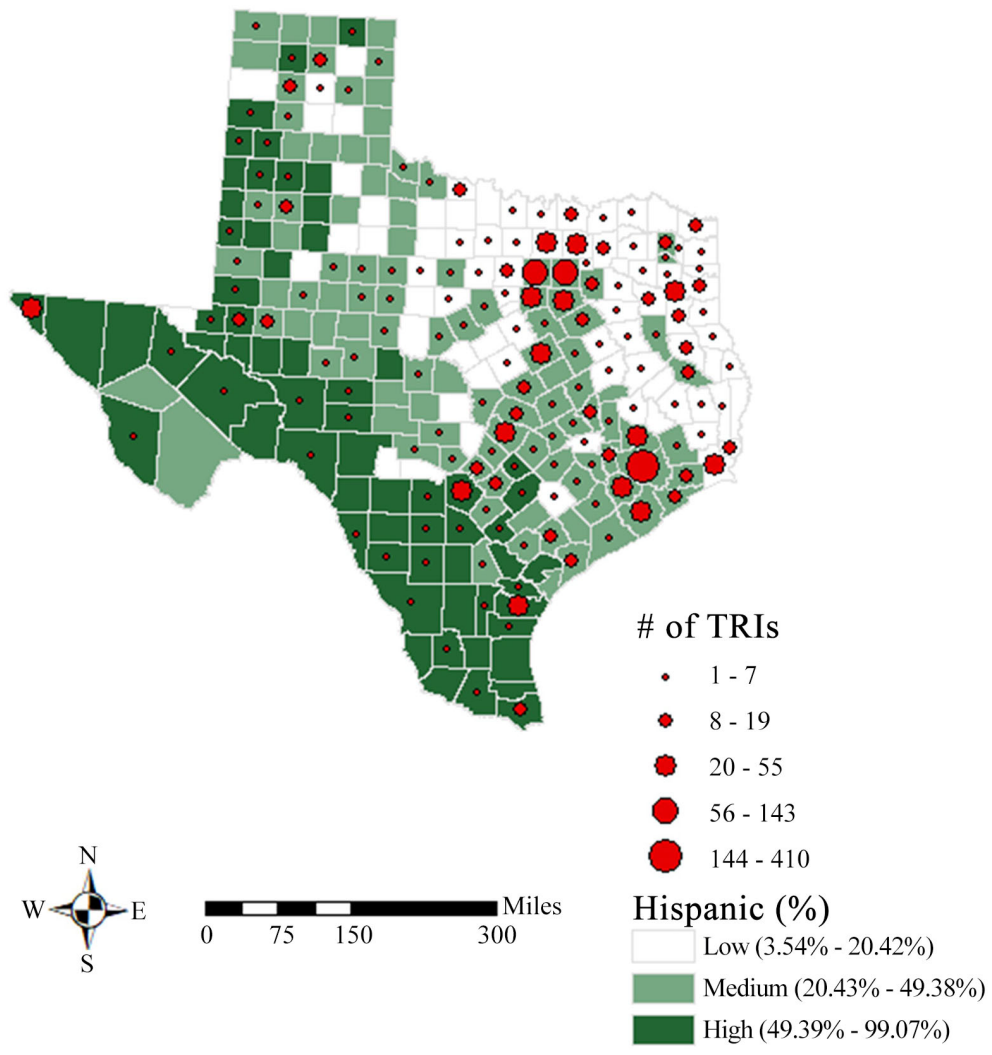

(c)

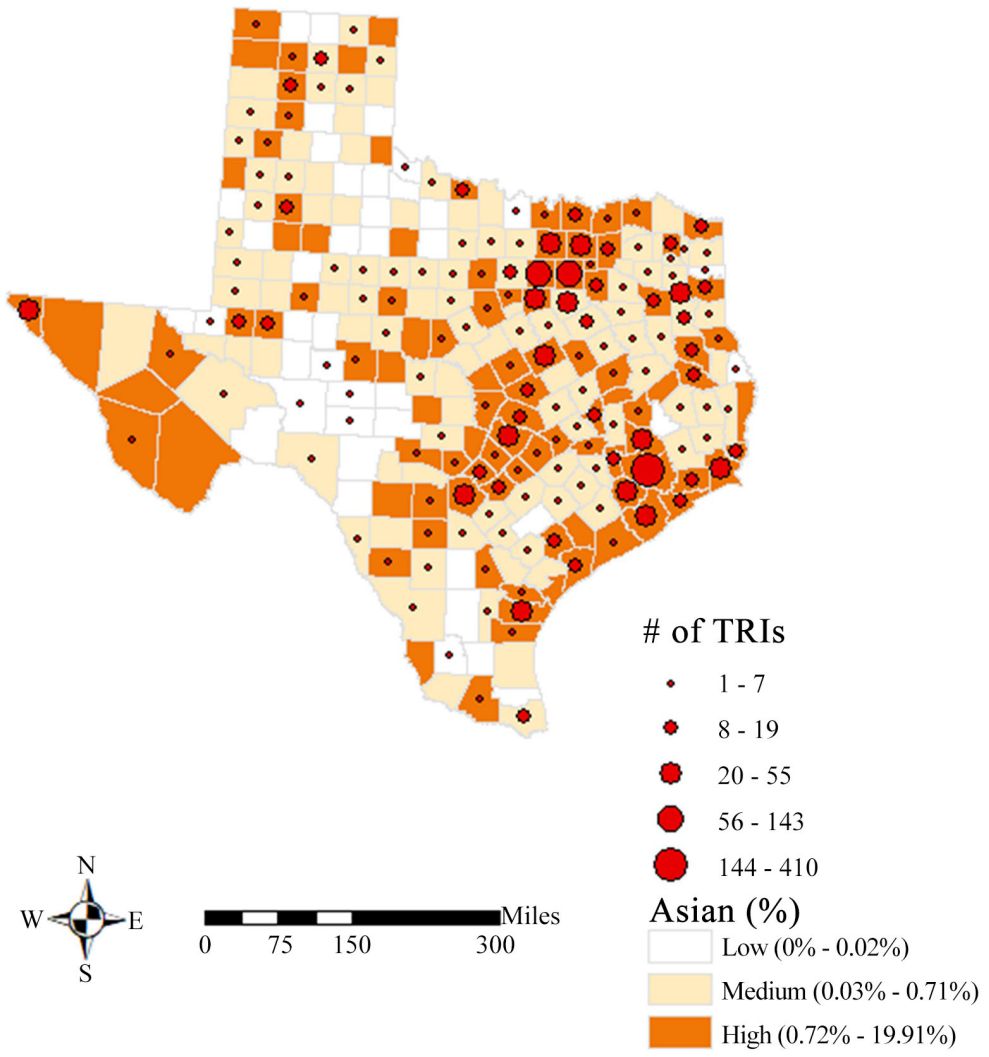

(d) 


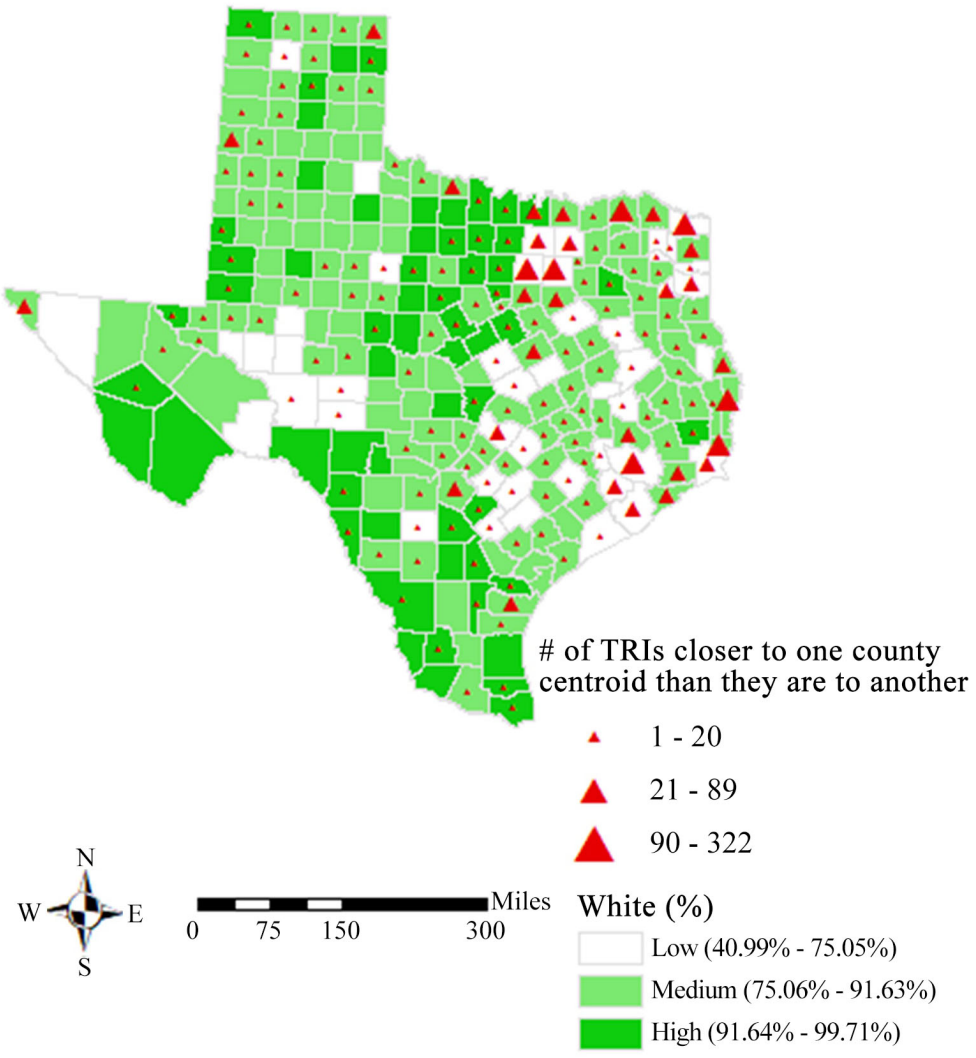

(e)
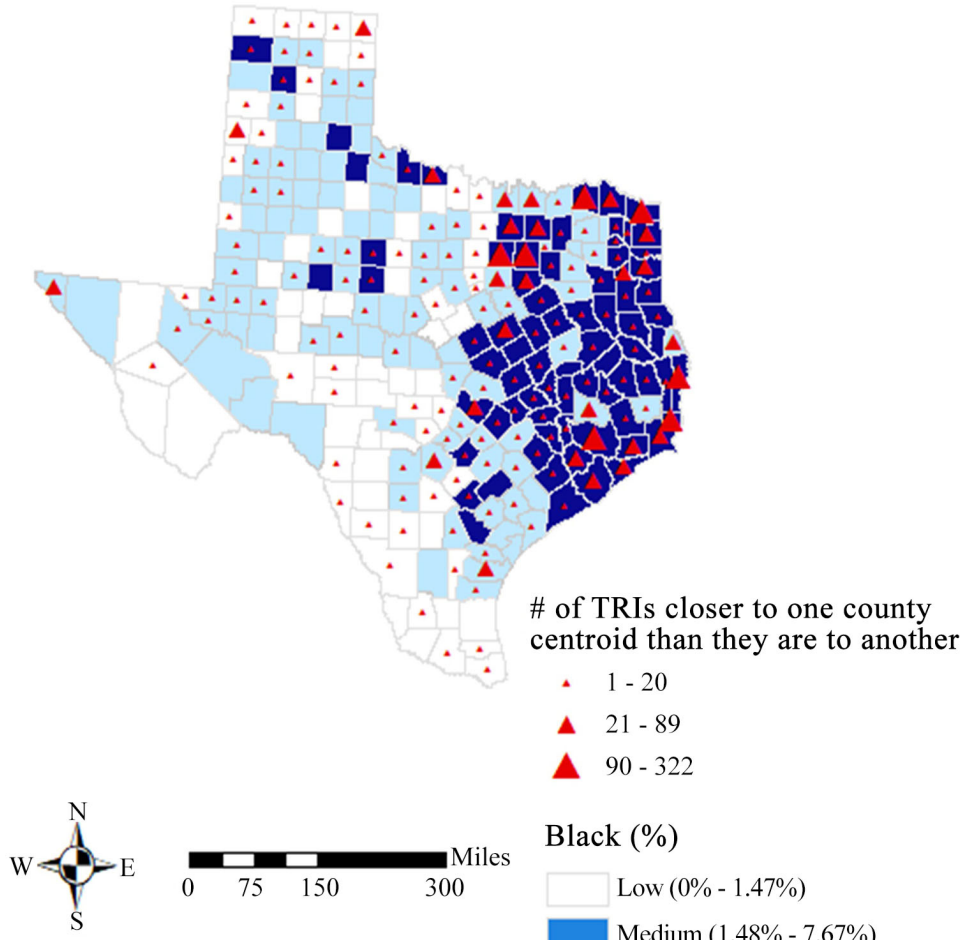

Black (\%)

Low $(0 \%-1.47 \%)$
Medium $(1.48 \%-7.67 \%)$
$\operatorname{High}(7.68 \%-33.84 \%)$

(f) 


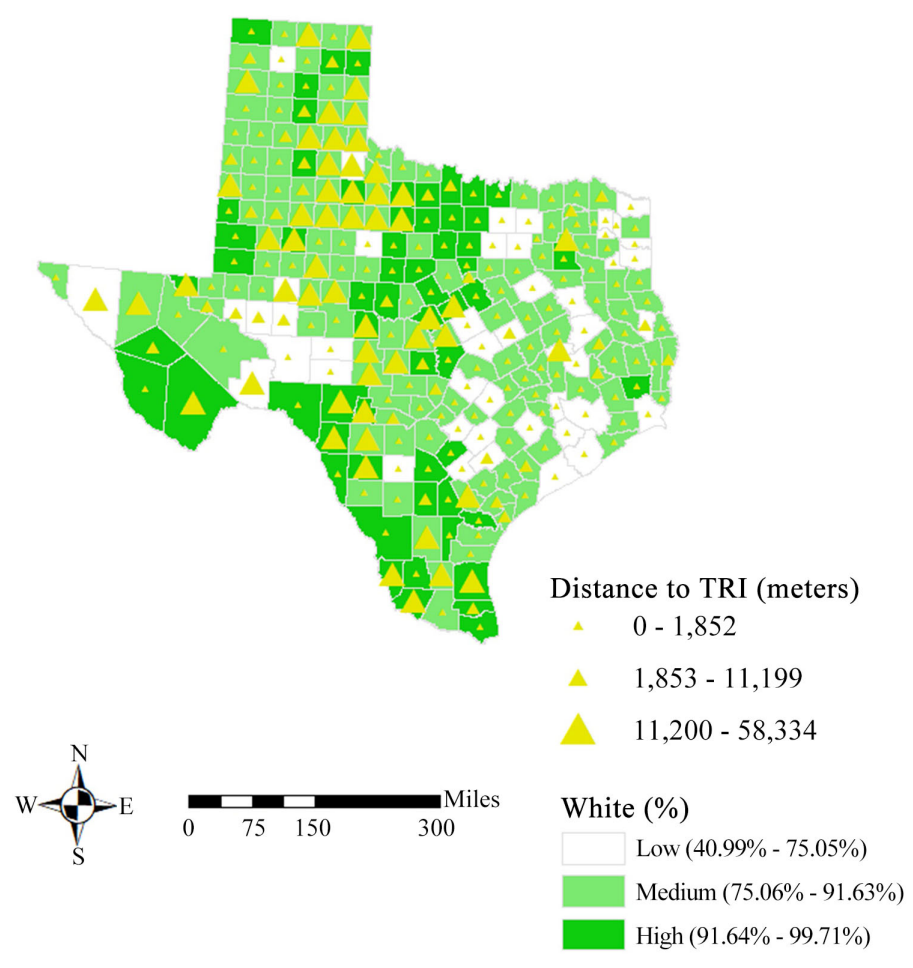

(g)

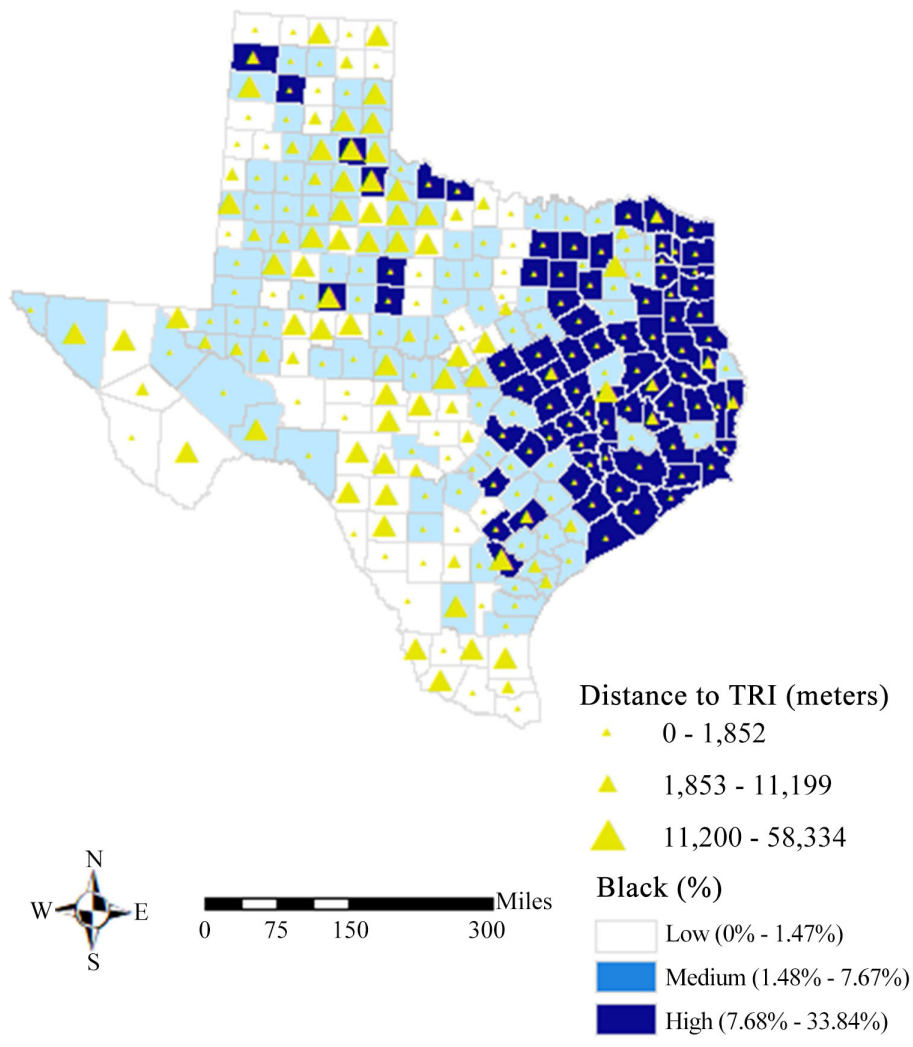

(h)

Figure 1. Relationships between race/ethnicity and the number of TRI facilities by county in texas. 


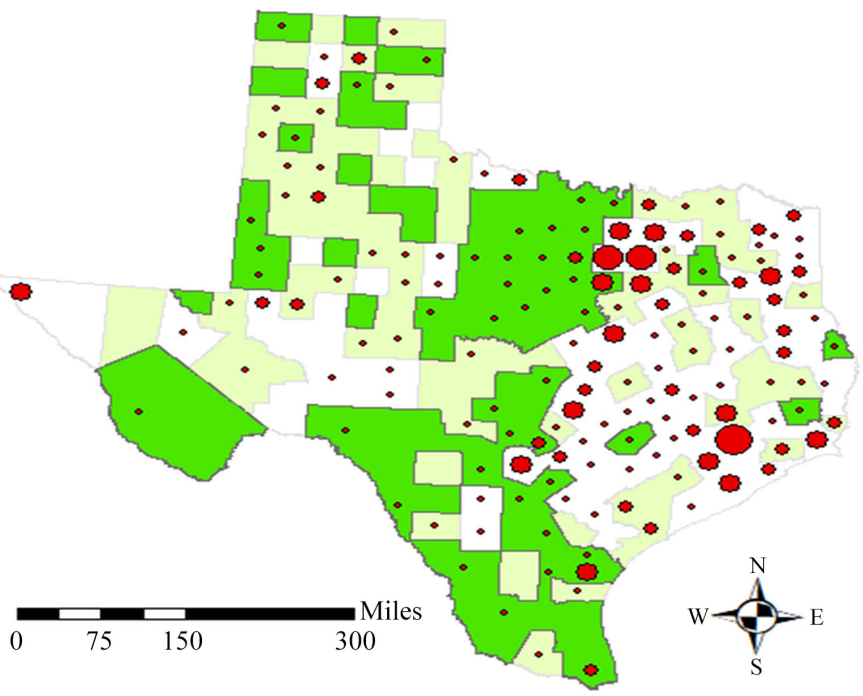

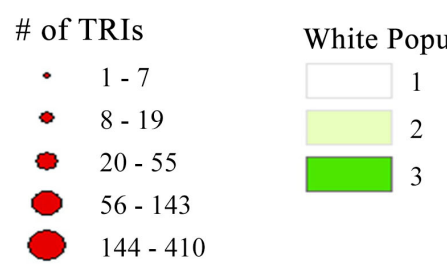

(a)

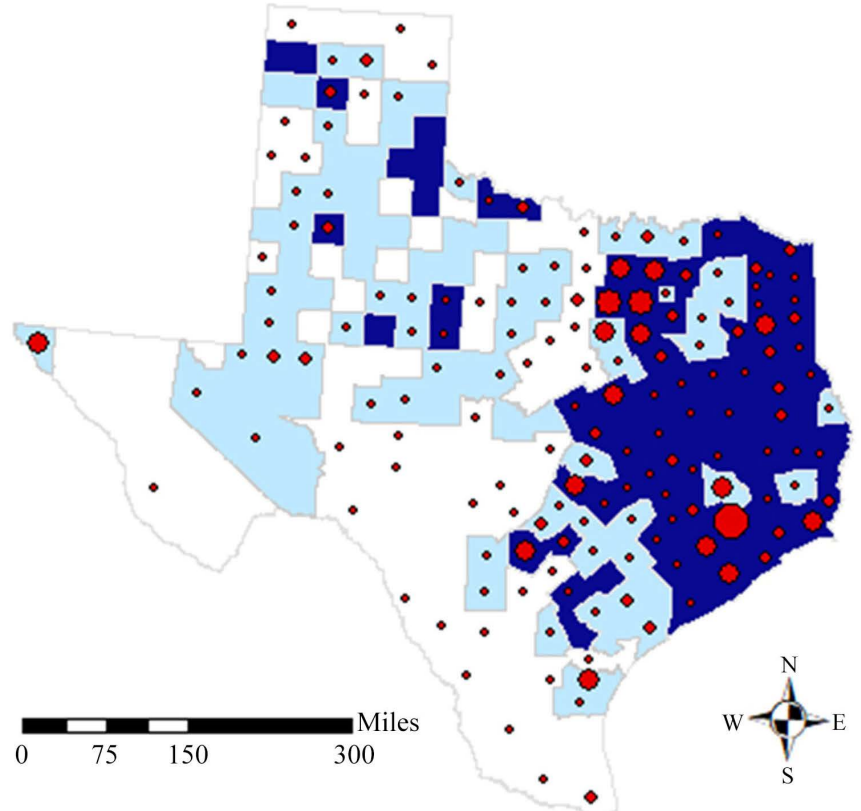

\begin{tabular}{ll|} 
\# of TRIs & \multicolumn{2}{c}{ Black Pop } \\
- $\quad 1-7$ & 1 \\
- $\quad 8-19$ & \\
- $20-55$ & \\
\hline$\quad 56-143$ & \\
\hline$\quad 144-410$ &
\end{tabular}

(b) 


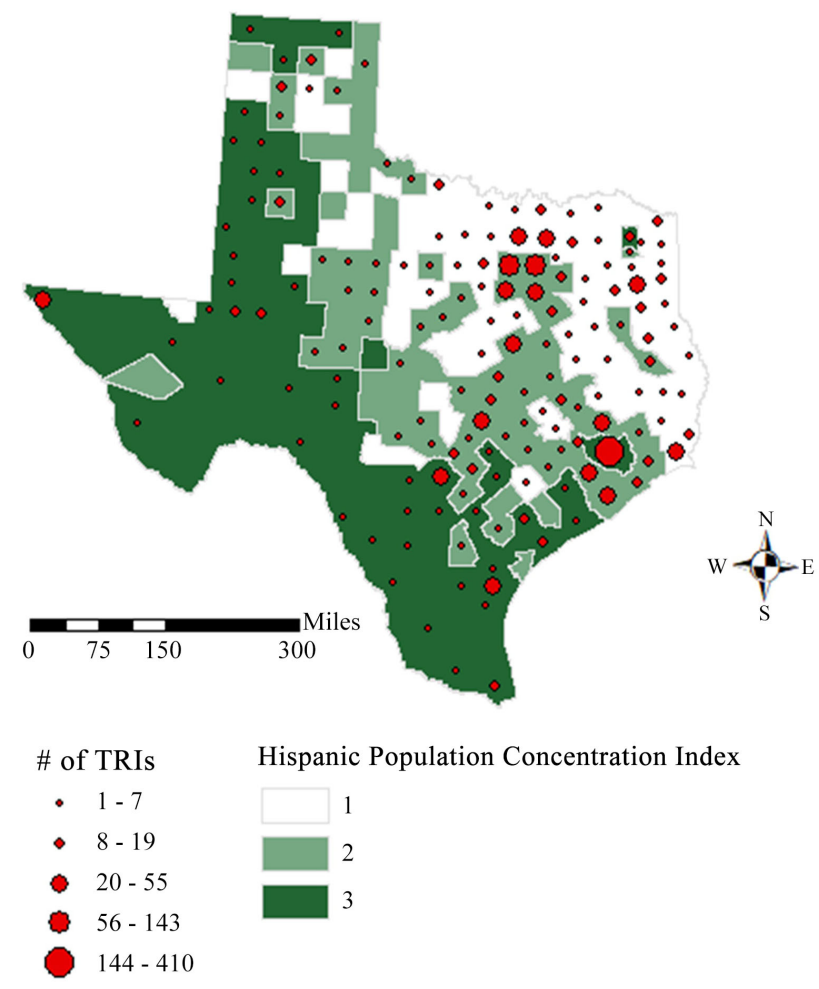

(c)

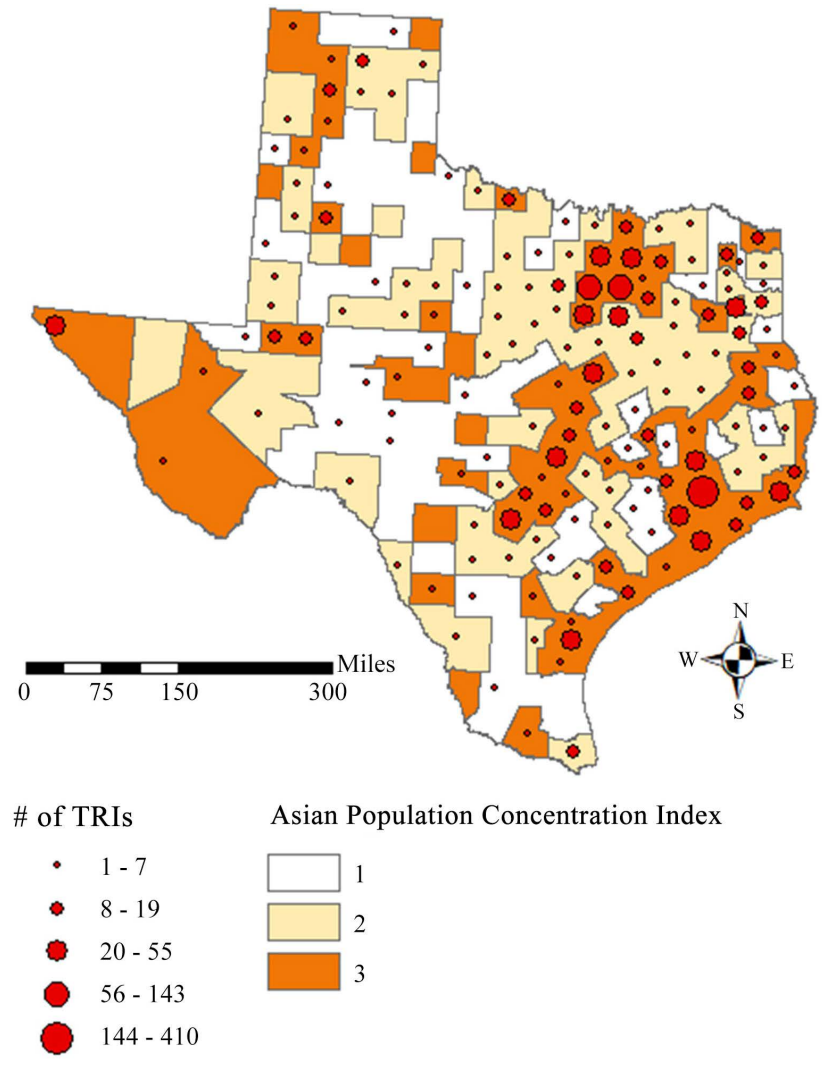

(d)

Figure 2. Race-specific population index in association with the number of TRI facilities. 
A spatial join operation was carried out to identify the total number of TRI facilities in each population concentration index. As shown in Table 2, the results show that the more the representation of the white population (i.e., Index three), the fewer the number of TRI facilities present in the given index, and vice versa. On the other hand, the statistics state that the more the representation of the black or Asian population (i.e., Index three), the more the number of TRI facilities present in the given index, and vice versa. Meanwhile, the number of TRI facilities was highest in Index 2 with the medium level of the Hispanic population.

Point density analysis was conducted by using the ArcGIS Point Density tool to quantify TRI facilities spread across the counties in Texas and to identify the chemical risk hot spots. The GIS tool enables ArcGIS users to estimate the density of input vector features composed of points around each of the output raster cells. The highest value range or hot spots were assigned "High" while the lowest value range or cold spots as "Low" to represent the risk level of hazardous material releases. The dark brown signals the highest level of chemical risk, while the white color, the lowest risk level among the three (see Figure 3(a)). The quantities were reassigned to each county through the ArcGIS Spatial Analyst

Table 2. Race/Ethnicity vs. the number of TRI facilities in texas.

\begin{tabular}{|c|c|c|c|c|}
\hline Race/Ethnicity & Index & Total Population* & Racial/Ethnic Population (\%) & \# of TRIs (\%) \\
\hline \multirow{3}{*}{ White } & 1 & $20,678,606$ & $\begin{array}{c}14,325,988 \\
(69.3 \%)\end{array}$ & $\begin{array}{c}1330 \\
(73.2 \%)\end{array}$ \\
\hline & 2 & $4,310,481$ & $\begin{array}{c}3,708,524 \\
(86.0 \%)\end{array}$ & $\begin{array}{c}297 \\
(16.3 \%)\end{array}$ \\
\hline & 3 & $2,896,108$ & $\begin{array}{c}2,686,177 \\
(93.0 \%)\end{array}$ & $\begin{array}{c}190 \\
(10.5 \%)\end{array}$ \\
\hline \multirow{3}{*}{ Black } & 1 & $2,868,562$ & $\begin{array}{l}20,964 \\
(0.7 \%)\end{array}$ & $\begin{array}{c}99 \\
(5.5 \%)\end{array}$ \\
\hline & 2 & $4,918,896$ & $\begin{array}{c}219,574 \\
(4.5 \%)\end{array}$ & $\begin{array}{c}328 \\
(18.0 \%)\end{array}$ \\
\hline & 3 & $20,097,737$ & $\begin{array}{c}3,125,245 \\
(15.5 \%)\end{array}$ & $\begin{array}{c}1390 \\
(76.5 \%)\end{array}$ \\
\hline \multirow{3}{*}{ Hispanic } & 1 & $4,825,923$ & $\begin{array}{l}752,838 \\
(15.6 \%)\end{array}$ & $\begin{array}{c}363 \\
(20.0 \%)\end{array}$ \\
\hline & 2 & $12,158,195$ & $\begin{array}{c}3,725,301 \\
(30.6 \%)\end{array}$ & $\begin{array}{c}773 \\
(42.5 \%)\end{array}$ \\
\hline & 3 & $10,901,077$ & $\begin{array}{c}6,443,417 \\
(59.1 \%)\end{array}$ & $\begin{array}{c}681 \\
(37.5 \%)\end{array}$ \\
\hline \multirow{3}{*}{ Asian } & 1 & 894,851 & $\begin{array}{c}1289 \\
(0.1 \%)\end{array}$ & $\begin{array}{c}64 \\
(3.5 \%)\end{array}$ \\
\hline & 2 & $3,278,863$ & $\begin{array}{l}19,923 \\
(0.6 \%)\end{array}$ & $\begin{array}{c}266 \\
(14.6 \%)\end{array}$ \\
\hline & 3 & $23,711,481$ & $\begin{array}{c}1,287,045 \\
(5.43 \%)\end{array}$ & $\begin{array}{c}1487 \\
(81.8 \%)\end{array}$ \\
\hline
\end{tabular}




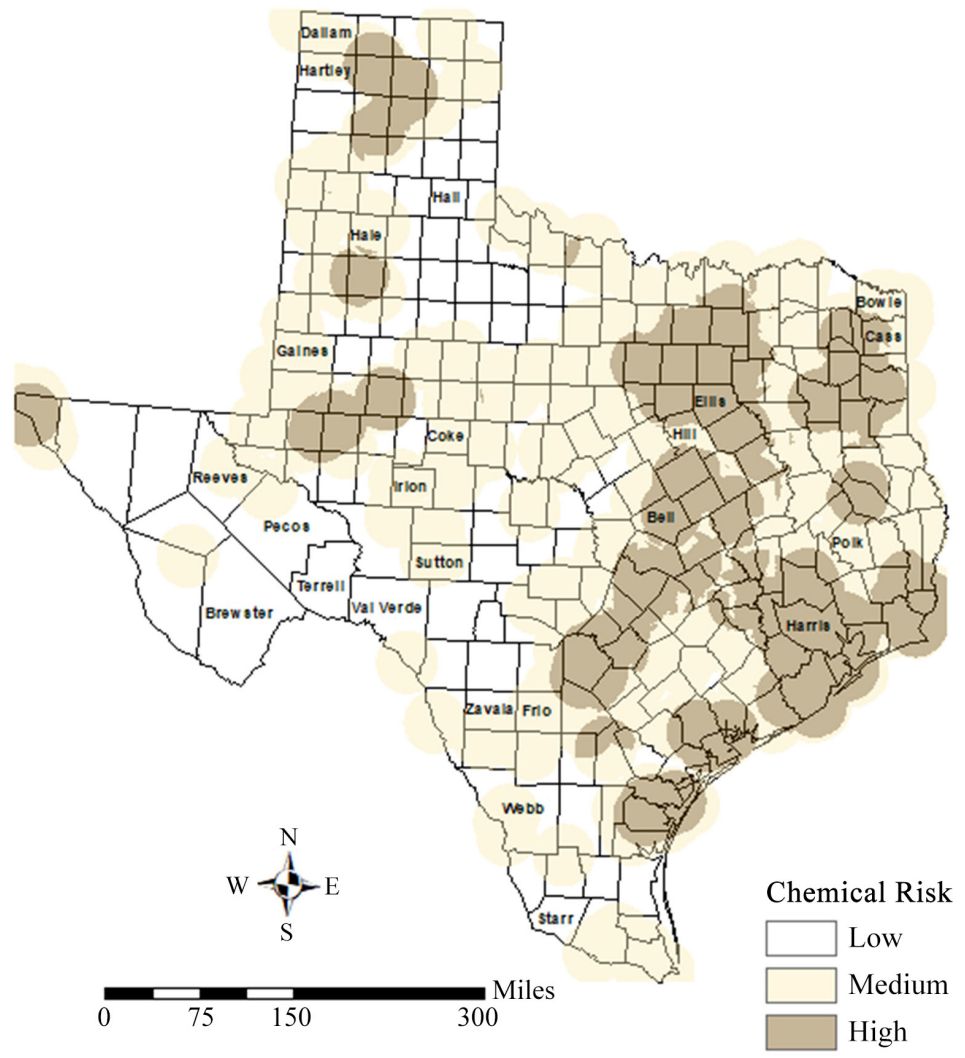

(a)

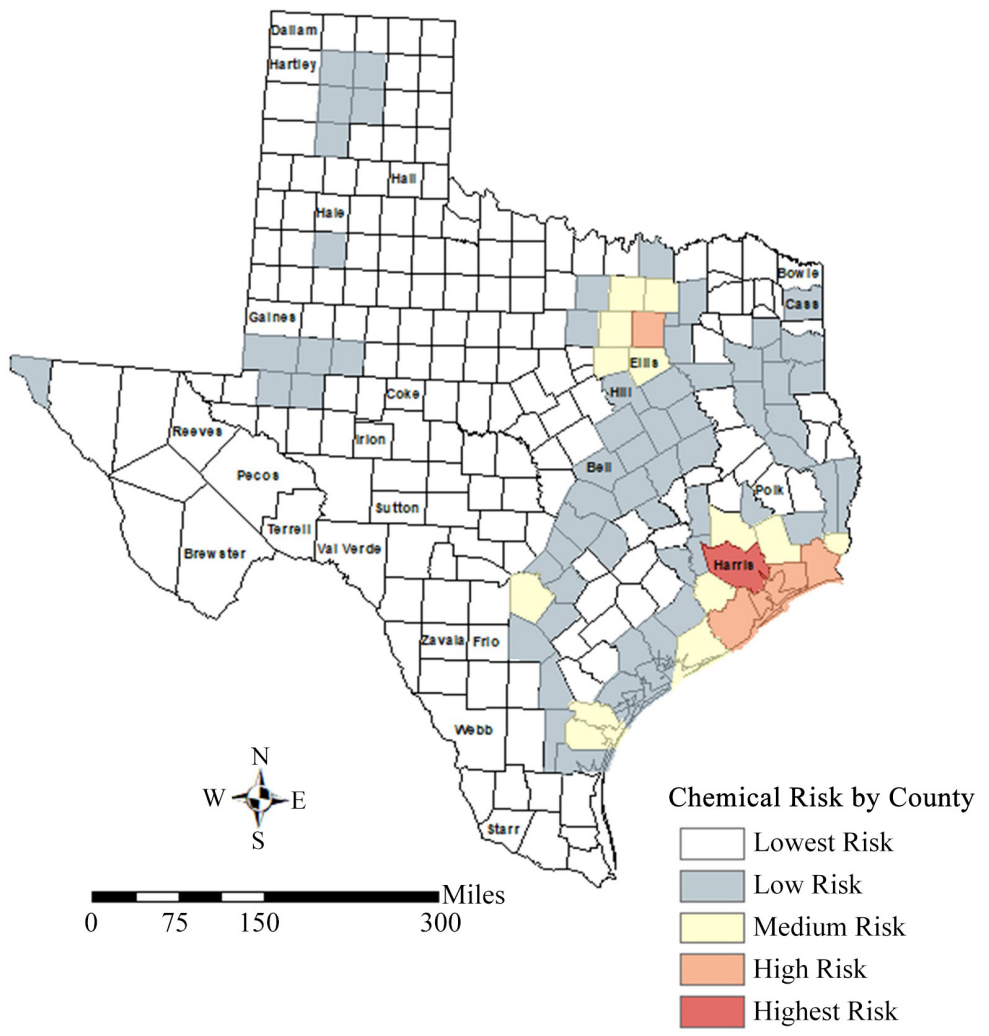

(b) 


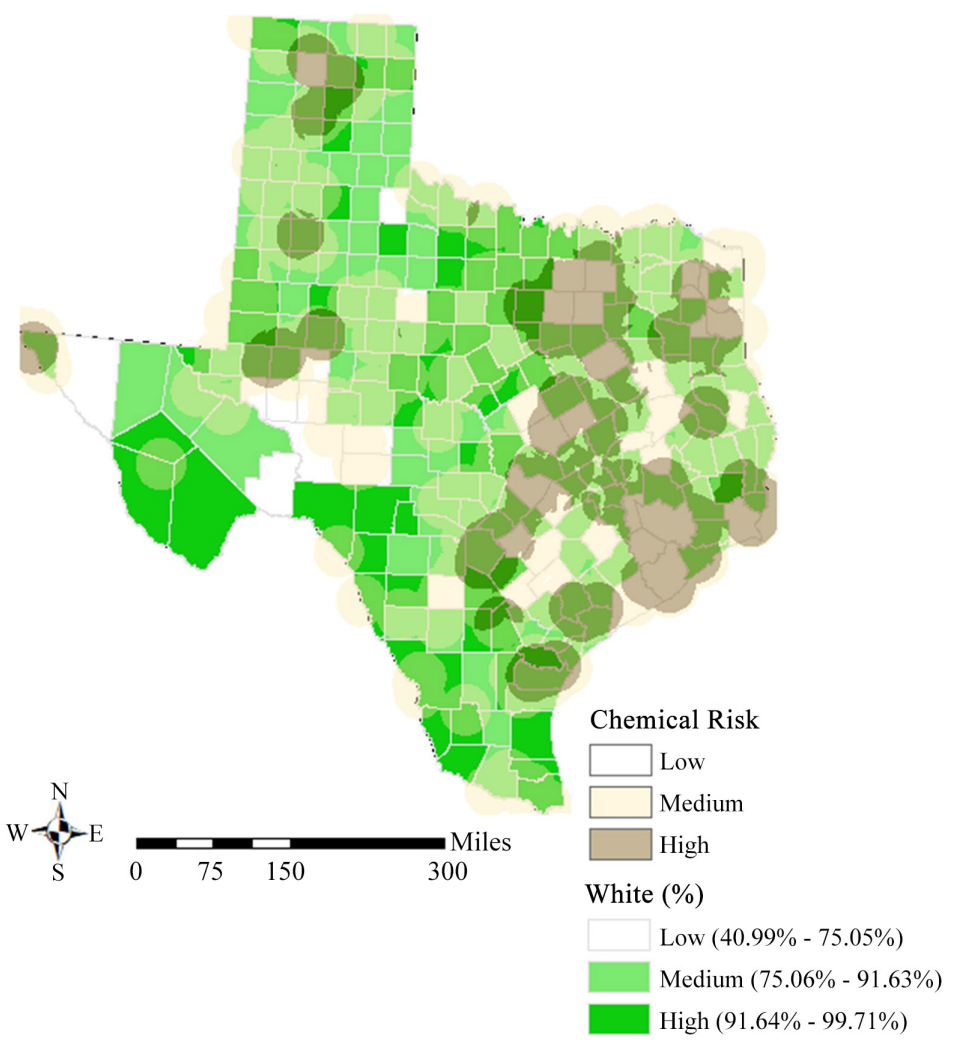

(c)

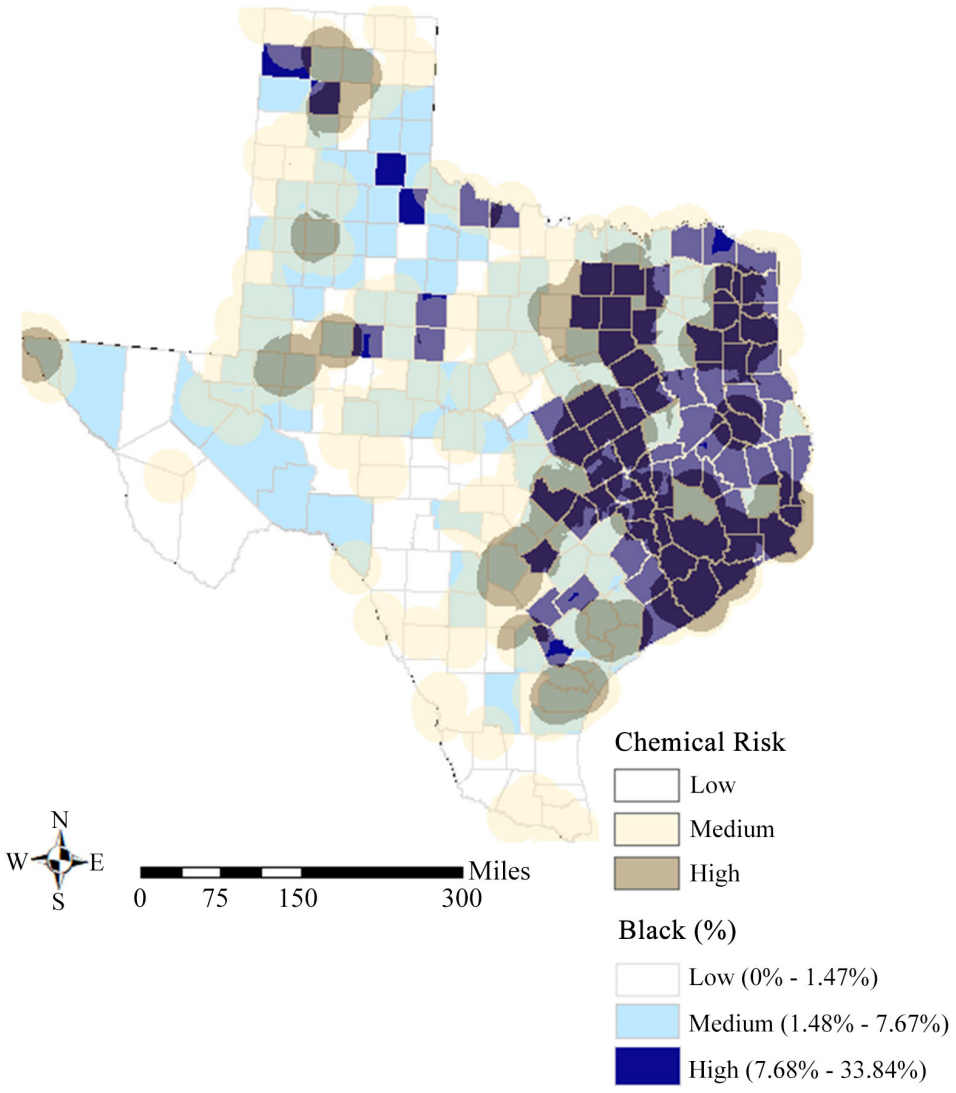

(d) 


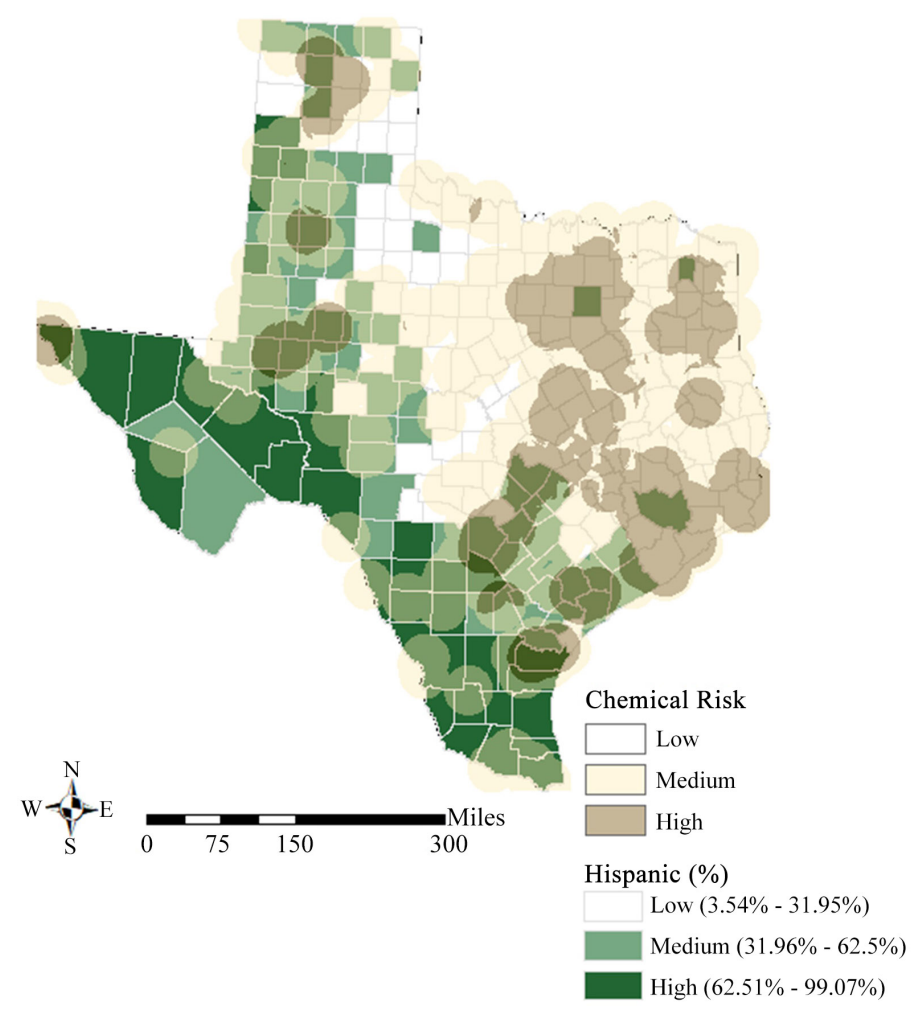

(e)

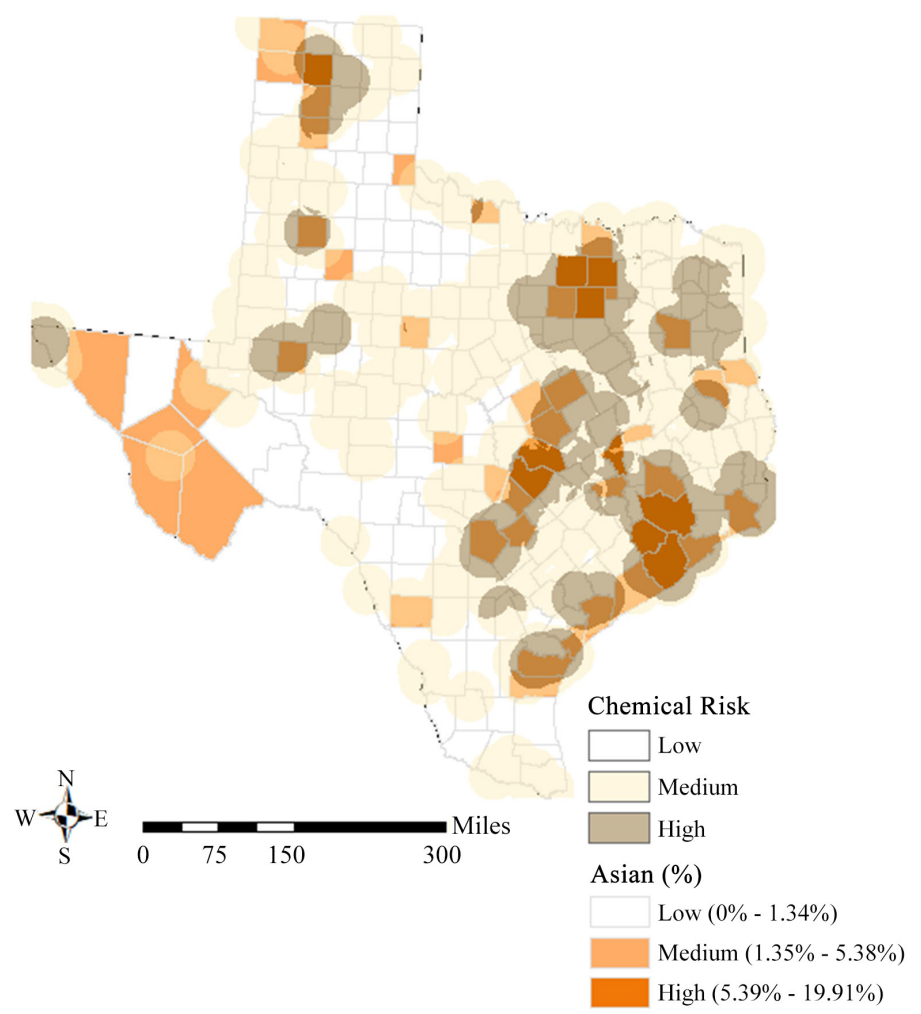

(f)

Figure 3. Relationships between race/ethnicity and chemical risk by county in texas. 
Geoprocessing tool called Zonal Statistics, which calculates statistics on values of the point density raster within the county vector dataset. This new raster providing a quick snapshot of which county belongs to the risk hot spots is displayed using the five classes, representing the county's chemical risk levels (see Figure $3(b)$ ). The point density raster was overlaid with each of the layers showing the levels of representation for the white, black, Hispanic, and Asian population (see Figures 3(c)-(f)). These maps show almost the same results as those discussed in the section titled "Relationships between Race and the Number of TRI Facilities by County in Texas." For example, According to Figure 3(c), white people tend to avoid the counties at a higher risk of hazardous material facilities. In contrast, according to Figures 3(d)-(f), the black and Asian populations are disproportionally concentrated in the counties with a higher level of chemical risk. Lastly, Figure 3(e) shows no or weak relationship between the Hispanic population and the scientifically measured chemical risk, considering that many areas with a higher and medium level of representation for the Hispanic people have a higher level of chemical risk.

Figure 4(a) and Figure 4(b) show how educational levels are associated with the risk of hazardous material releases at the county level. Observation shows no relationship between educational attainment and chemical risk. The "No Schooling Rate" or the percentage of the population with a BA or higher degree and the chemical risk (i.e., \# of TRI facilities in each county) has no relation. Namely, it means that a higher level of the "no schooling rate" is not related to a higher level of chemical risk at the county level. However, Figure 4(c) and Figure 4(d) show how education levels correlate with the chemical risk at a more detailed geographical resolution, such as the census tract level. According to Figure 4(c), It is evident that the higher the no schooling rate, the higher the chemical risk. In the same manner, Figure 4(d) supports a solid relationship between the educational level (i.e., the percentage of the population with a BA or higher degree) and the chemical risk. These maps indicate that people with a higher level of educational attainment would prefer to reside in communities with a lower level of chemical risk.

Figure 5(a) and Figure 5(b) delineate how income levels are associated with the risk of hazardous material releases at the county level. The results show the geographic patterns like the previous results indicating the relationship between educational attainment and the chemical risk, as seen in the section above. What is clear is that the median household income and the rate of household income with $\$ 200,000$ or higher are not in the range of TRI facilities in each county, suggesting that a higher level of income level is not related to a higher level of chemical risk at the county level. However, Figure 5(c) and Figure 5(d) show how income levels correlate with the chemical risk at a more detailed geographical level, such as the census tract level. What seems to be apparent in Figure (y) is that the higher the income (i.e., the median household income), the higher the chemical risk. In the same manner, Figure 5(d) supports a solid relationship between 


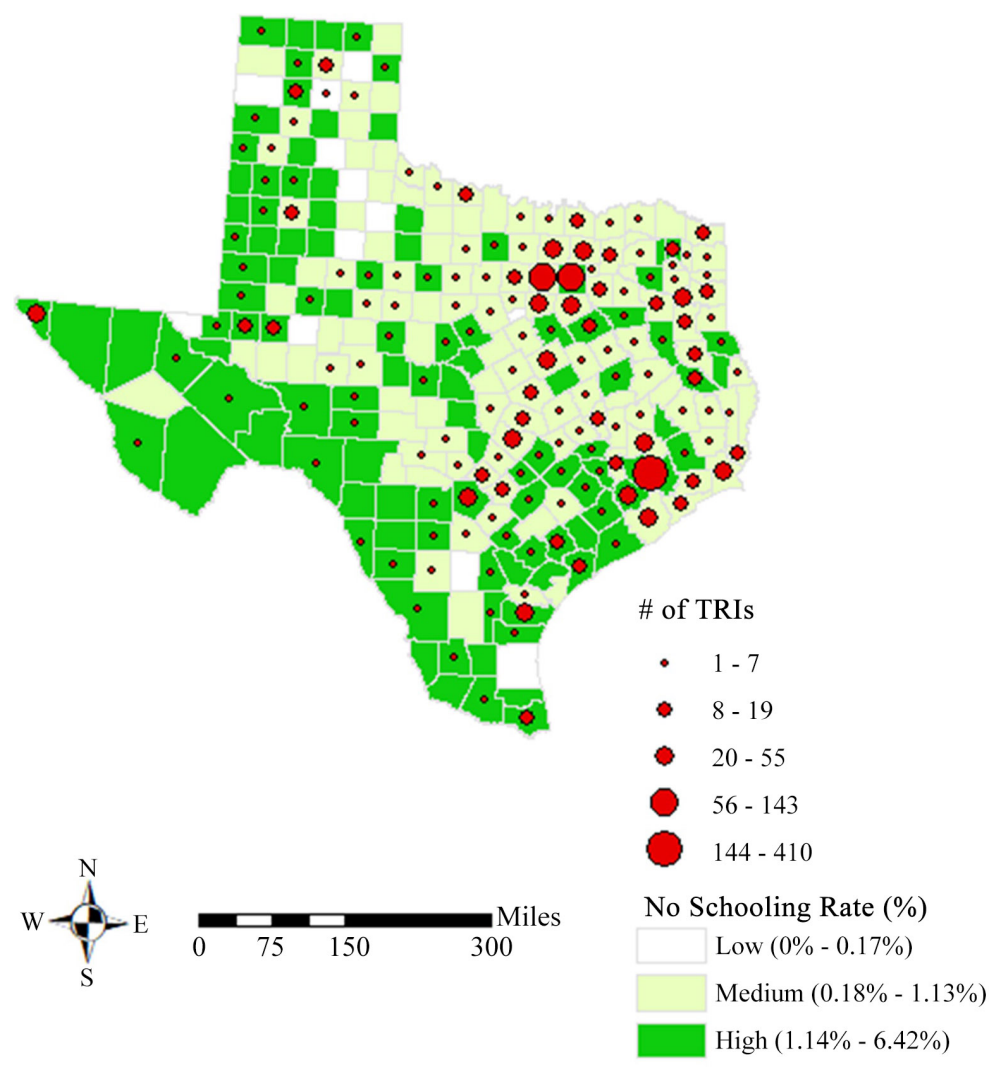

(a)

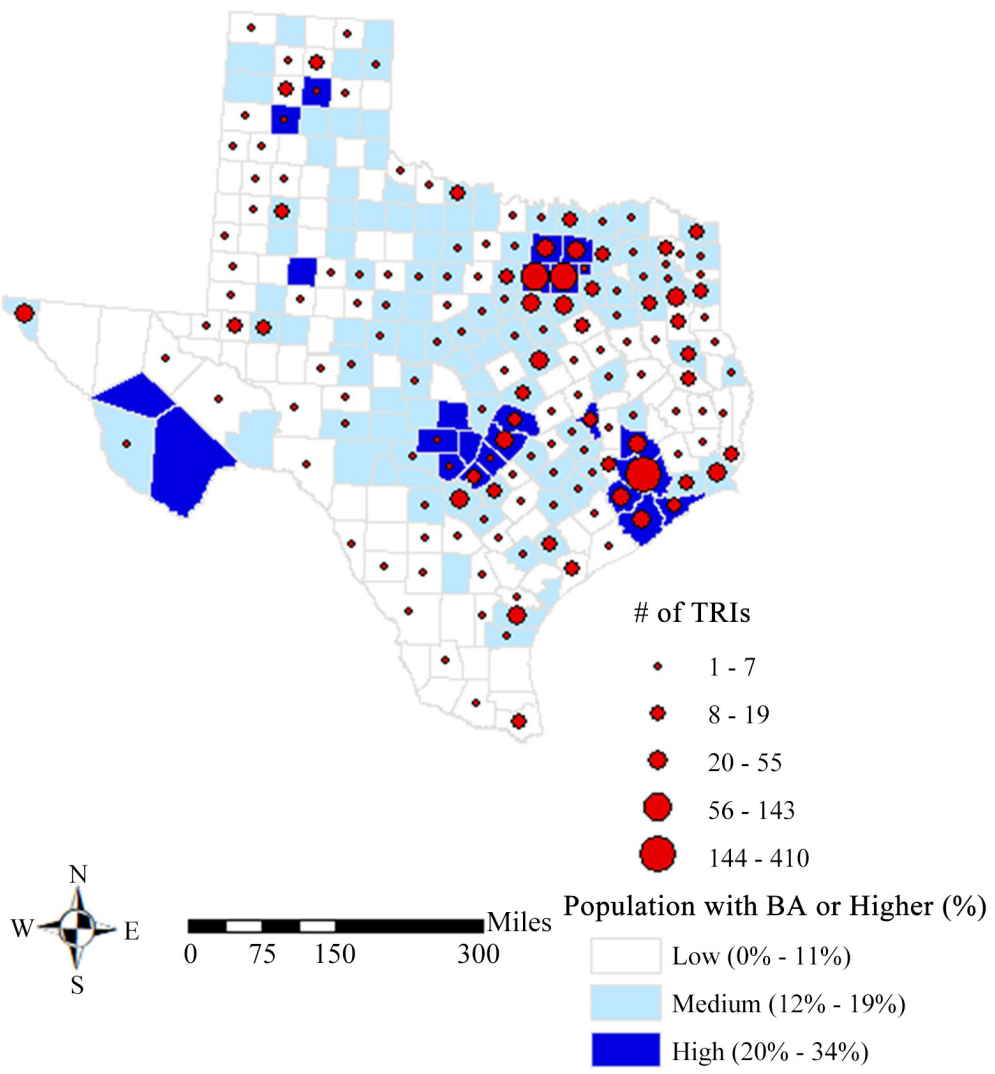

(b) 


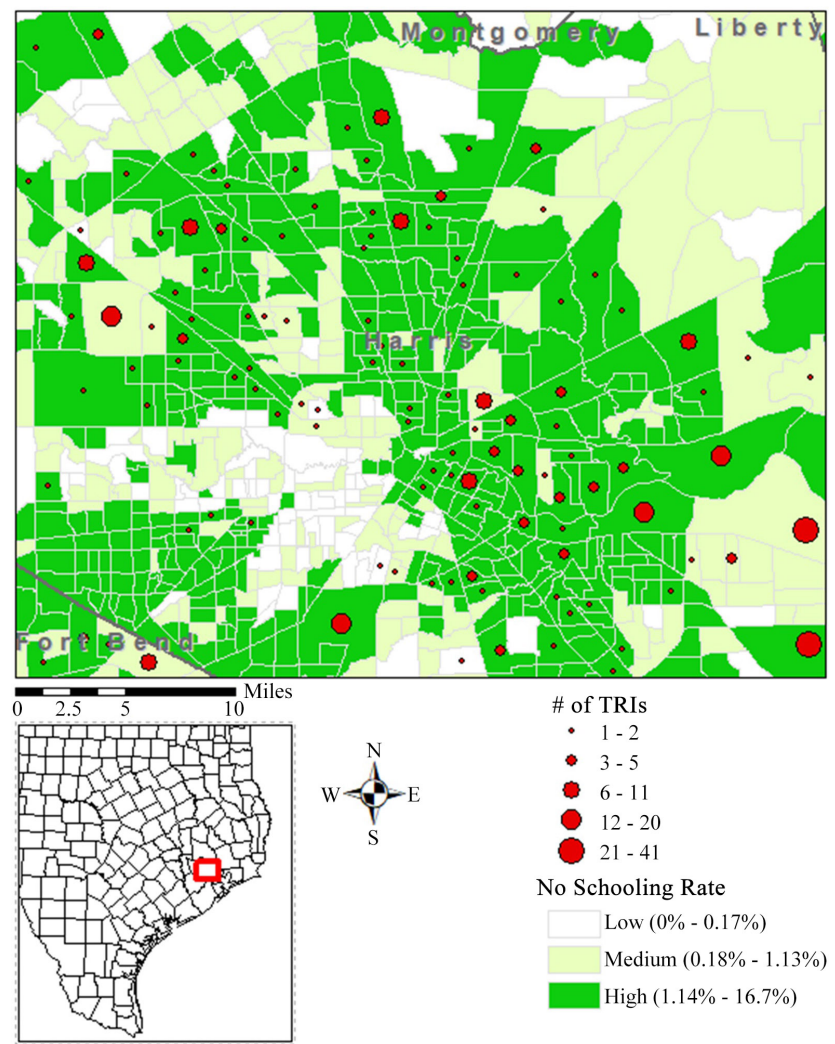

(c)

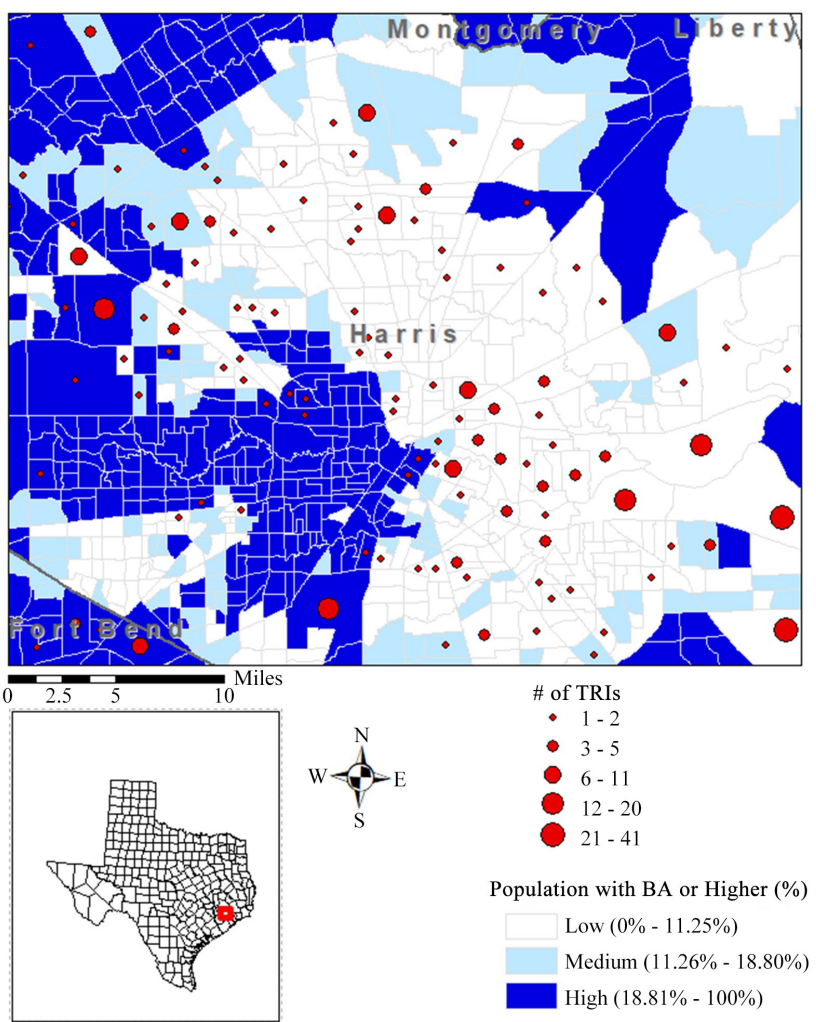

(d)

Figure 4. Relationships between educational level and chemical risk. 

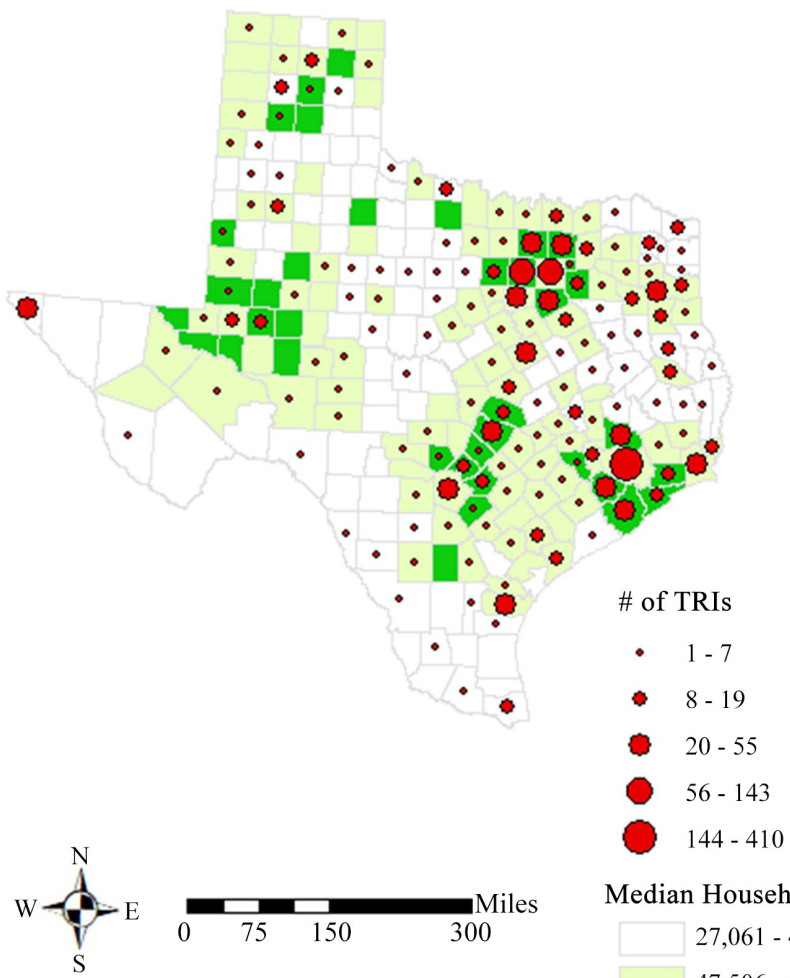

Median Household Income (\$) $27,061-47,505$ $47,506-63,778$

$63,779-95,561$

(a)

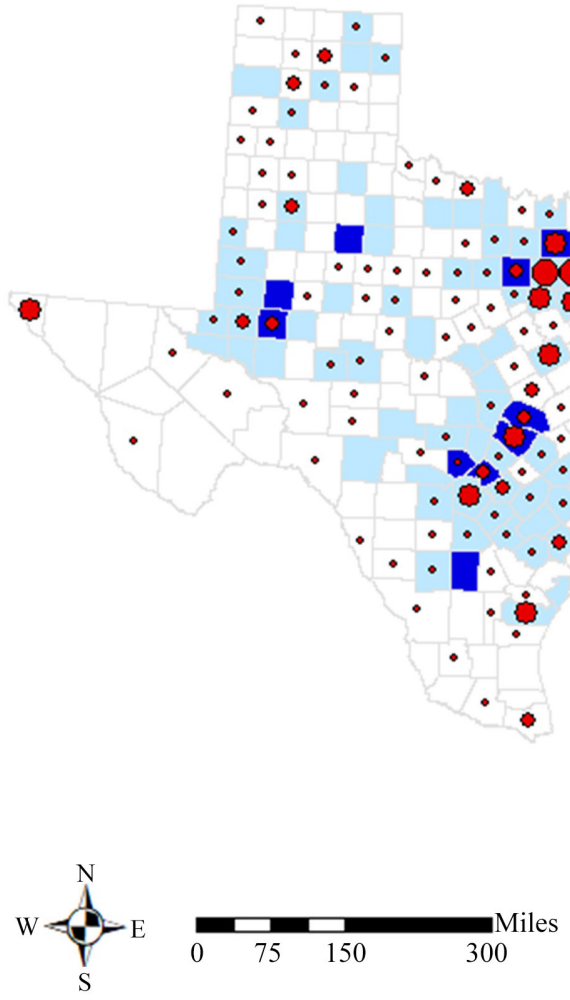

\# of TRIs

- $1-7$

- 8 - 19

20-55

$56-143$

$144-410$

Rate of Household Income with $\$ 200 \mathrm{k}$ or higher (\%) $0 \%-3.53 \%$ $3.54 \%-7.78 \%$ $7.79 \%-15.87 \%$

(b) 


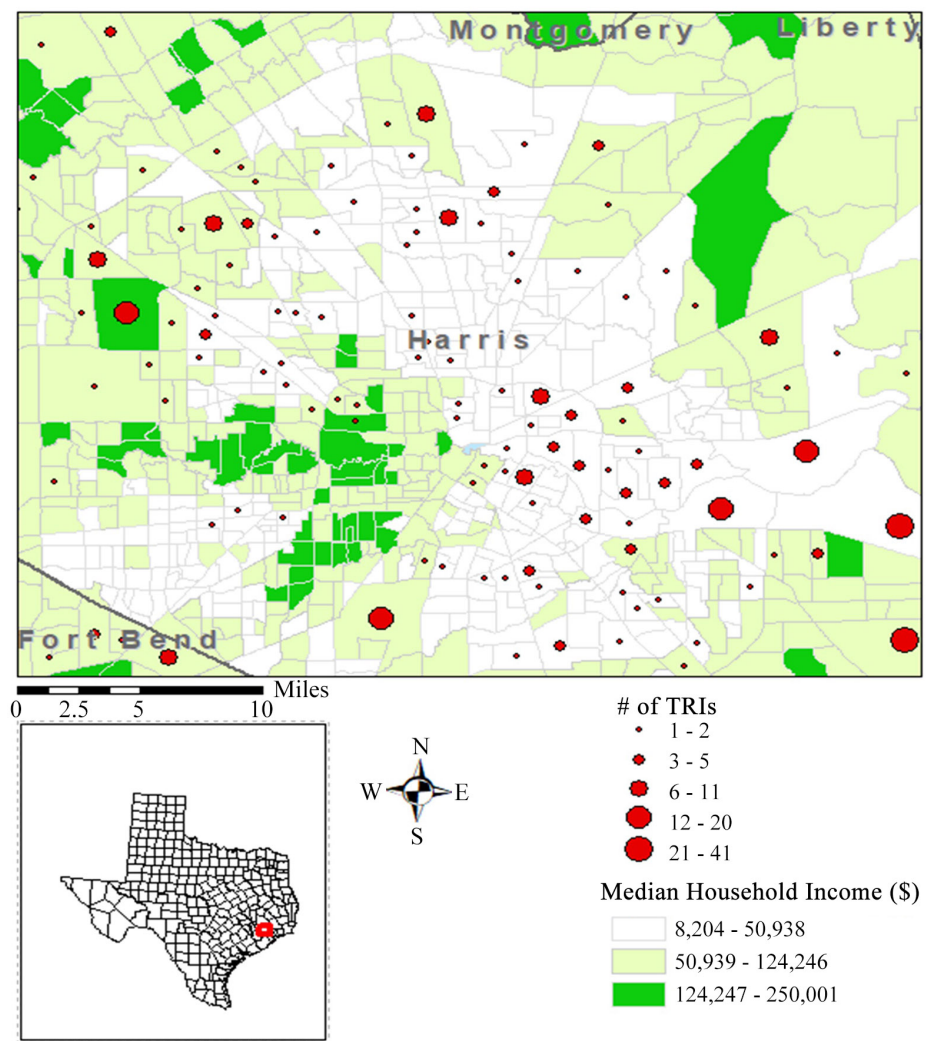

(c)

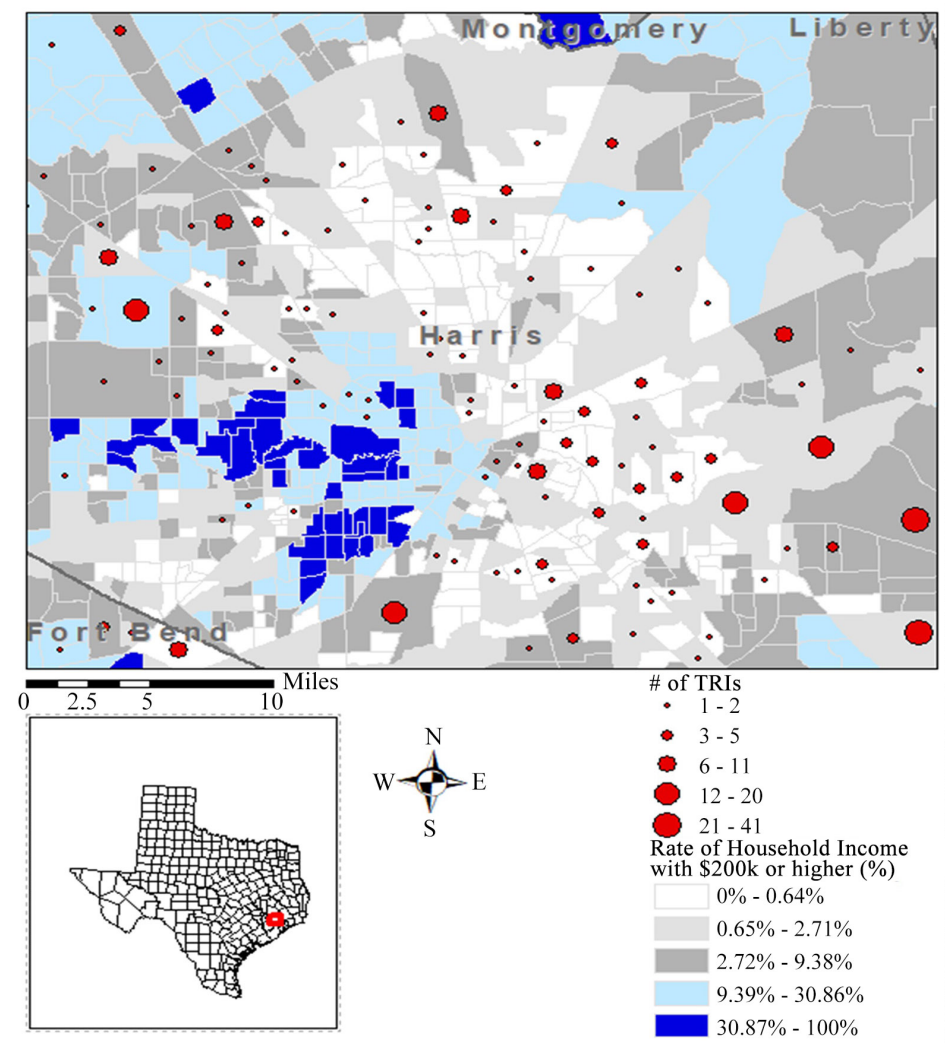

(d)

Figure 5. Relationships between income level and chemical risk. 
the income level (i.e., the rate of household income with $\$ 200,000$ or higher) and the chemical risk. These maps indicate that people with a higher level of household income would prefer to reside in communities with a lower level of chemical risk.

\section{Conclusion}

It is apparent that identifying and tracking technological hazards and the community at risk should be conducted through what is referred to as risk identification and vulnerability analysis. It is primary step in the risk management and hazard reduction paradigm. Such confirmed risk factors will be communicated to the risk managers and policymakers to establish communication and develop hazard-related public policies and regulations, which, in turn, contribute to leading to improving emergency management.

The present study attempts to analyze the risk of exposure to hazardous materials release and its relations with socioeconomic demographics. To be more specific, this research aimed to identify the location and extent of areas subject to the technological hazard and to reveal how race, ethnicity, income levels, and educational attainments are related to the risk of the hazard at the county and census tract levels in the state of Texas. This research showed the technological hazard-prone communities have a comparatively higher representation for the minority populations such as blacks and Asians. On the contrary, the white population tends to avoid residing in communities subject to technological hazards. The study results can be used as a basis for future decisions of policymakers to prevent or reduce the impacts of a technological disaster on communities.

Additionally, the geographical patterns explored in the study will help develop and calibrate the regulation of the release/treatment of hazardous materials. This research suggests that emergency managers and urban planners should identify which part of their community is vulnerable to technological hazards. It will also help them better prepare for, respond to, recover from such a human-made hazard, and mitigate its potential harmful effect if a disaster should strike. In addition, the research would contribute to helping the policymakers aware of the current hazard situations and keeping them better prepared for chemical hazards. Lastly, it would help the residents to better understand the circumstance to mitigate the consequences at the individual level as well as increase their awareness to prepare for and respond to the uncertainties in the hotspots involved in high risk of the hazards.

\section{Conflicts of Interest}

The authors declare no conflicts of interest regarding the publication of this paper.

\section{References}

Ak, R., Bahrami, M., \& Bozkaya, B. (2020). A Time-Based Model and GIS Framework for 
Assessing Hazardous Materials Transportation Risk in Urban Areas. Journal of Transport \& Health, 19, Article ID: 100943. https://doi.org/10.1016/j.jth.2020.100943

Andersen, Z. J., Stafoggia, M., Weinmayr, G., Pedersen, M., Galassi, C., Jørgensen, J. T., Raaschou-Nielsen, O. et al. (2017). Long-Term Exposure to Ambient Air Pollution and Incidence of Postmenopausal Breast Cancer in 15 European Cohorts within the ESCAPE Project. Environmental Health Perspectives, 125, Article ID: 107005. https://doi.org/10.1289/isee.2016.3966

Batisse, E., Goudreau, S., Baumgartner, J., \& Smargiassi, A. (2017). Socioeconomic Inequalities in Exposure to Industrial Air Pollution Emissions in Quebec Public Schools. Canadian Journal of Public Health, 108, e503-e509. https://doi.org/10.17269/CJPH.108.6166

Chakraborty, J. (2020). Unequal Proximity to Environmental Pollution: An Intersectional Analysis of People with Disabilities in Harris County, Texas. The Professional Geographer, 72, 521-534. https://doi.org/10.1080/00330124.2020.1787181

Dolinoy, D. C., \& Miranda, M. L. (2004). GIS Modeling of Air Toxics Releases from TRIReporting and Non-TRI-Reporting Facilities: Impacts for Environmental Justice. Environmental Health Perspectives, 112, 1717-1724. https://doi.org/10.1289/ehp.7066

EPA (2019). 2019 TRI Factsheet: State-Texas. https://enviro.epa.gov/triexplorer/tri_factsheet.factsheet_forstate?pstate=TX\&pyear=20 19\&pParent=TRI\&pDataSet=TRIQ1

EPA (2021). Toxics Release Inventory (TRI) Program. https://www.epa.gov/toxics-release-inventory-tri-program

Flores, A. B., Castor, A., Grineski, S. E., Collins, T. W., \& Mullen, C. (2021). Petrochemical Releases Disproportionately Affected Socially Vulnerable Populations along the Texas Gulf Coast after Hurricane Harvey. Population and Environment, 42, 279-301. https://doi.org/10.1007/s11111-020-00362-6

Gong, X., Lin, Y., \& Zhan, F. B. (2018). Industrial Air Pollution and Low Birth Weight: A Case-Control Study in Texas, USA. Environmental Science and Pollution Research, 25, 30375-30389. https://doi.org/10.1007/s11356-018-2941-y

Johnson, R., Ramsey-White, K., \& Fuller, C. H. (2016). Socio-Demographic Differences in Toxic Release Inventory Siting and Emissions in Metro Atlanta. International Journal of Environmental Research and Public Health, 13, 747. https://doi.org/10.3390/ijerph13080747

Johnston, J. E., Werder, E., \& Sebastian, D. (2016). Wastewater Disposal Wells, Fracking, and Environmental Injustice in Southern Texas. American Journal of Public Health, 106, 550-556. https://doi.org/10.2105/AJPH.2015.303000

Kates, R. W., \& Kasperson, J. X. (1983). Comparative Risk Analysis of Technological Hazards (A Review). Proceedings of the National Academy of Sciences, 80, 7027-7038. https://doi.org/10.1073/pnas.80.22.7027

Li, H., Wang, Q. G., Yang, M., Li, F., Wang, J., Sun, Y., Qian, X. et al. (2016). Chemical Characterization and Source Apportionment of PM2.5 Aerosols in a Megacity of Southeast China. Atmospheric Research, 181, 288-299. https://doi.org/10.1016/j.atmosres.2016.07.005

Lowry, J. H., Miller, H. J., \& Hepner, G. F. (1995). A GIS-Based Sensitivity Analysis of Community Vulnerability to Hazardous Contaminants on the Mexico/US Border. Photogrammetric Engineering and Remote Sensing, 61, 1347-1359.

Maantay, J. (2007). Asthma and Air Pollution in the Bronx: Methodological and Data Considerations in Using GIS for Environmental Justice and Health Research. Health \& Place, 13, 32-56. https://doi.org/10.1016/j.healthplace.2005.09.009 
Malecha, M. L., Kirsch, K. R., Karaye, I., Horney, J. A., \& Newman, G. (2020). Advancing the Toxics Mobility Inventory: Development and Application of a Toxics Mobility Vulnerability Index to Harris County, Texas. Sustainability: The Journal of Record, 13, 282291. https://doi.org/10.1089/sus.2020.0067

Palmer, R. F., Blanchard, S., Stein, Z., Mandell, D., \& Miller, C. (2006). Environmental Mercury Release, Special Education Rates, and Autism Disorder: An Ecological Study of Texas. Health \& Place, 12, 203-209. https://doi.org/10.1016/j.healthplace.2004.11.005

Poku-Boansi, M., Tornyeviadzi, P., \& Adarkwa, K. K. (2018). Next to Suffer: Population Exposure Risk to Hazardous Material Transportation in Ghana. Journal of Transport \& Health, 10, 203-212. https://doi.org/10.1016/j.jth.2018.06.009

Quddus, N., Yu, M., Tamim, N., Rahmani, S., \& Mannan, M. S. (2018). Risk Assessment of Class 3 (PG II \& III) Hazardous Materials in Transportation. Process Safety Progress, 37, 376-381. https://doi.org/10.1002/prs.11967

Santella, N., Steinberg, L. J., \& Sengul, H. (2010). Petroleum and Hazardous Material Releases from Industrial Facilities Associated with Hurricane Katrina. Risk Analysis: An International Journal, 30, 635-649. https://doi.org/10.1111/j.1539-6924.2010.01390.x

Senouci, R., Taibi, N. E., Teodoro, A. C., Duarte, L., Mansour, H., \& Yahia Meddah, R. (2021). GIS-Based Expert Knowledge for Landslide Susceptibility Mapping (LSM): Case of Mostaganem Coast District, West of Algeria. Sustainability, 13, 630. https://doi.org/10.3390/su13020630

Sheppard, E., Leitner, H., McMaster, R. B., \& Tian, H. (1999). GIS-Based Measures of Environmental Equity: Exploring Their Sensitivity and Significance. Journal of Exposure Analysis \& Environmental Epidemiology, 9, 18-28. https://doi.org/10.1038/sj.jea.7500023

Sohrabi, S., Zietsman, J., \& Khreis, H. (2020). Burden of Disease Assessment of Ambient Air Pollution and Premature Mortality in Urban Areas: The Role of Socioeconomic Status and Transportation. International Journal of Environmental Research and Public Health, 17, 1166. https://doi.org/10.3390/ijerph17041166

Sriramachari, S. (2004). The Bhopal Gas Tragedy: An Environmental Disaster. Current Science, $86,905-920$.

Thakur, P., Ganguly, R., \& Dhulia, A. (2018). Occupational Health Hazard Exposure among Municipal Solid Waste Workers in Himachal Pradesh, India. Waste Management, 78, 483-489. https://doi.org/10.1016/j.wasman.2018.06.020

Thomas, J. K., Qin, B., \& Richardson, B. E. (2002). Economic and Toxic Chemical Influences on Rates of Gynecological Cancer Mortality in Texas. Human Ecology Review, 9, 43-54.

Wattigney, W. A., Rice, N., Cooper, D. L., Drew, J. M., \& Orr, M. F. (2009). State Programs to Reduce Uncontrolled Ammonia Releases and Associated Injury Using the Hazardous Substances Emergency Events Surveillance System. Journal of Occupational and Environmental Medicine, 51, 356-363. https://doi.org/10.1097/JOM.0b013e318197368e

Xu, Y., Wu, X., Kumar, R., Barth, M., Diao, C., Gao, M., Meehl, G. A. et al. (2020). Substantial Increase in the Joint Occurrence and Human Exposure of Heatwave and HighPM Hazards over South Asia in the Mid-21st Century. AGU Advances, 1, e2019AV000103. https://doi.org/10.1029/2019AV000103

Zhao, M., \& Liu, X. (2017). Reprint of: Regional Risk Assessment for Urban Major Hazards Based on GIS Geoprocessing to Improve Public Safety. Safety Science, 97, 112-119. https://doi.org/10.1016/j.ssci.2016.03.028 